\title{
AS PEQUENAS FRATERNIDADES ORGANIZADAS EM TORNO DA ESPIRITUALIDADE E DA PARTILHA DE VIDA
}

\section{The small fraternities organized around the spirituality and the life sharing}

\author{
Miro Leopoldo Reckziegel ${ }^{a}$, N edio Antonio Seminottib, João Vitor H aeberle Jaeger \\ a Mestre em Psicologia So cial e dos G rupos, Assessor-psicólogo do Centro de Pastoral da Pontifícia Universidade Católica do \\ Rio G rande do Sul (PUCRS), Porto A legre, RS - Brasil, e-mail: miro.reckziegel@ pucrs.br \\ b Professor PPG Psicologia da Pontifícia Universidade Católica do Rio G rande do Sul (PUCRS), Coordenador do G rupo de \\ Pesquisa Processos e O rganização dos Pequenos G rupos, Porto Alegre, RS - Brasil, e-mail: nedio.seminotti@ pucrs.br \\ c G raduando de Psicologia, Bolsista de Iniciação Científica da Pontifícia UniversidadeCatólica do Rio G randedo Sul (PUCRS), \\ Porto Alegre, RS - Brasil, e-mail:joaojaeger@ hotmail.com
}

\begin{abstract}
Resumo
Apresentamos um relatório de pesquisa de uma rede composta por pequenos grupos, as Fraternidades Maristas. Esta rede é posta em discussão, articulando-se a teoria sistêmica-complexa, a noção de rede e de pequenos grupos como sistemas complexos. Apoiam, ainda, a discussão, noçõ̃es de espiritualidade, de amizade, partilha de vida e pertença. Tem como objetivos conhecer e compreender os motivos pelos quais as pessoas se agregam em Pequenas Fraternidades do Movimento Champagnat da Família Marista e de como vivem a espiritualidade. Justificou o trabalho o pouco conhecimento que se tem sobre os motivos pelos quais as pessoas se agregam a essas Fraternidades e os aportes que isso traz às suas vidas, às suas famílias e ao seu meio social; existem poucos dados sociodemográficos sobre as fraternidades e seus participantes; não se tem conhecimento de uma dissertação de mestrado ou tese de doutorado, em Psicologia, sobre as Pequenas Fraternidades Maristas. A pesquisa teve uma abordagem quantitativa e qualitativa. O s instrumentos de coleta foram: um Q uestionário Fechado, Autoaplicável, o G rupo Focal e o D iário de Campo. O s resultados indicam que entre os motivos mais significativos pelos quais as pessoas aderem às fraternidades estão a espiritualidade, o convívio, a amizade, ajuda na educação dos filhos, entre outros.
\end{abstract}

Palavras-chave: Fraternidade. Espiritualidade marista. Pequeno grupo. Sistemas complexos. 


\begin{abstract}
We present a research report about a network composed of small groups, the Marist Fraternities. It is being discussed by articulating the complex systemic theory, the notion of network and small groups as complex systems. The Fraternities advocate the discussion, notions of spirituality, friendship, life sharing and belonging. The aim is to know and understand the reasons why people have joined Small Fraternities of Champagnat Movement of the Marist Family and how they experience spirituality. The justification of this work has been the little knowledge we have about the motives why people join those Fraternities and subsides that this fact brings to their lives, their families and their social environment. There have been little social-demographic data on fraternities and their participants. No reports either of a Psychology dissertation or thesis about Small Marist Fraternities have been found. The research has had both a quantitative and qualitative approach. The data-gathering instruments were a Closed, Self-Applicable Questionnaire, a Focus Group, and the Field Diary. The results have pointed that the most significant reasons why people join fraternities include: spirituality, coexistence, friendship, and support in child-rearing, among others.
\end{abstract}

Keywords: Fraternity. Marist spirituality. Small group. Complex systems.

\section{INTRODUÇÃO}

As Fraternidades Maristas, como pequenos grupos, foram tema de pesquisa de mestrado. Integram aredemundial do Movimento Champagnat da Família Marista (MChFM). Foram criadas no final do século passado e fazem parte delas pessoas filiadas ao Instituto Marista, jovens, pais de alunos Maristas, colaboradores, antigos alunos, amigos dos Irmãos Maristas, entre outros.

O objetivo principal do estudo foi conhecer e compreender os motivos pelos quais as pessoas se agregam em Pequenas Fraternidades do MChFM e como vivem a espiritualidade. Propôs-se também a mapear as características e os contextos sociais em que vivem as pessoas que se agregam às Fraternidades, compreender as formas de pertença à Fraternidade Marista, saber se a experiência da pertença ao grupo é algo inédito em suas vidas e conhecer algum aporte que a pertença traz às suas vidas e ao seu meio social.

Parasituaro leitor, damos alguns conceitos das teorias e seus autores que ajudaram na compreensão desses grupos. A primeira teoria foi a dos Pequenos Grupos. Conforme Back (1979), o pequeno grupo é uma unidade estável que vive em algum lugar entre 0 indivíduo e a sociedade. As Fraternidades são constituídas de 4a 15 participantes (Marista, 1990). Isso vem ao encontro do que diz Anzieu (1978), que o pequeno grupo deve ter de 7 a 15 integrantes, pois, chegado a um patamar, uma variação quantitativa gera um salto qualitativo. 0 pequeno grupo tem uma organização, geralmente em círculo, tal que todos podem se ver, ouvir, conhecer e ter reconhecidas as suas singularidades (Seminotti, Borges \& Cruz, 2004).

O segundo iluminador teórico utilizado para compreender as Fraternidades em estudo foi 0 de rede integrando sistemas complexos. Para Serres (1994), rede é uma pluralidade de pontos, religados entre si por uma pluralidade de ramificações ou nós. Contém um laço invisível interno e externo que o conecta ao Cosmo (Musso, 2001). As Fraternidades, como grupos humanos, isto é, sistemas orgânicos, do ponto de vista da biologia do social, compreendem os sistemas sociais humanos e estes conduzem à ideia de nichos dentro de nichos mais amplos (Maturana \& Varela, 2005).

Olhada do ponto de vista de sistemas complexos, a organização desses grupos remete a uma compreensão da organização complexa, como terceiro referencial teórico, pois alimenta um elo entre a desorganização (entropia) e a reorganização (neguentropia), ou seja, é um sistema complexo no qual seus participantes mantêm relações que não se deterioram em seu processo, mas, ao contrário, têm uma sinergia, uma espiritualidade, uma amizade que por si própria, constitui, mantém e desenvolve recursivamente o grupo, visando um nível sistêmico mais elevado (Morin, 2006). Os sistemas complexos 
apresentam uma infinidade de interações e de interferências intra e intersistêmicas que supõem incertezas, indeterminações, fenômenos aleatórios, 0 acaso. Essa organicidade social é compreendida segundo trêsprincípios básicos: o dialógico, arecursão organizacional e o hologramático (Morin, 2006). Por meio do princípio dialógico tenta-se superar a visão dialética da realidade que tende a eliminar os contrários pela produção de uma síntese. Acolhe os contrários, dialoga com os opostos, permite manter a dualidade, complementaridade e a contradição no seio da unidade. Supõe a dinâmica da recursividade, retroalimentação e contempla as emergências que decorrem das relações. As Fraternidades, vistas a partir do princípio dialógico, representam um campo vasto de situações eidentidades dos seus participantes que requerem essa flexibilidade e abertura para contemplar todos os aspectos presentes no grupo e fazerdelesemergênciasquecontribuam naconstrução do seu projeto e sua ação social.

0 princípio da recursão organizacional significa que "um processo recursivo éum processo em que os produtos e os efeitos são, ao mesmo tempo, causas e produtores do que os produz" (Morin, 2006, p. 74). Com isso contemplam-se rupturas com a linearidade, objetividade e estabilidade como questões únicas e absolutas na organização social. Nos pequenos grupos, assim como no grupo da Fraternidade, a recursividade se efetiva pelo crescimento que seus participantes geram nos demais e que retorna para eles, recursivamente, fazendo-os crescer pessoalmente (Alves \& Seminotti, 2006).

O princípio hologramático indica que "não apenas a parte está no todo, mas o todo está na parte" (Morin, 2006, p. 74). No grupo, como o da Fraternidade, o participante representa a família, a sociedade. 0 sujeito leva para a família, à sociedade a sinergia desenvolvida no grupo e vice-versa. Estabelece-se assim uma recursividade hologramática, na qual o indivíduo nunca está só, mas é rede e está em rede.

A espiritualidade se manifesta entre o finito e o infinito nas profundezas do ser humano (Kivitz, 2007, p. 34). É ainda, diz ainda o autor, um retorno àexperiênciabásicaparaalém desuas sistematizações. É uma indagação pelo sentido último das coisas que abre caminho para novas experiências. A espiritualidade, vivencida pelas Fraternidades, segue o princípio dialógico de Morin (2005, 2006), para contemplar as múltiplas dimensões do ser humano.
0 autor utilizar também o conceito de noosfera, termo forjado por Teilhard de Chardin, na década de 1920, para designar as coisas do espírito, com a finalidade de integrar essa dimensão humana, tanto em sua especificidade quanto na universalidade, segundo o princípio hologramático do pensamento complexo. A espiritualidade Marista, por sua vez, tem algumas especificidades, a saber: é mariana e apostólica. É apostólica porque segue os ensinamentos dos A póstolos e procura testemunhar, por sua vida e atitudes, os valores evangélicos no ambiente em que cada um vive. É mariana porque tem napessoadeMariaseu modelo deação pedagógica como educadora de Jesus, de seguimento de seu Divino Filho e de vivência cristã. A Espiritualidade Marista tem três fontes de inspiração, a saber: "os mistérios do Presépio, da Cruz e do Altar" (Maristas, C 7, 1987). 0 Presépio de Belém ensina a inocência, a simplicidade de vida, a doçura no trato com os demais. No despojamento de um D eus que se fez pequenino e frágil pode-se perceber a pobreza e a fragilidade das crianças e jovens. A Cruz ensina 0 amor sem reservas de $D$ eus por suas criaturas e como o sofrimento pode tornar-se redentor. Aprendemos ainda a humilde fidelidade no amor e aproxima-nos daspessoasque são atingidas pelo fracasso, sofrimento e que lutam pelo pão, ajustiça e a paz. E o Altar, lugar da comunhão com Jesus Cristo que se dá como alimento e nos torna aptos a nos doar também aos mais pobres, presenteando-os com o dom da nossa presença, tempo e recursos (Maristas, 2007).

D iante do exposto até aqui, dialogando entreanoção deFraternidade, compreendida como rede, pequeno grupo, sistema complexo, vivendo uma espiritualidade, emergiu a questão que norteou o estudo: por que pessoas se reúnem nesses grupos, neles permanecem e que ganhos deles obtêm?

As pequenas fraternidades integram a rede mundial do Movimento Champagnat da Família Marista, presente em nossa região, em forma de uma rede particular, as Fraternidades Maristas. Entre elas foram escolhidas 12, eleitas por um critério de conveniência, localizadas na Grande Porto Alegre, para realizar a pesquisa.

\section{MÉTODO}

O método usado foi umaabordagem mista, integrada por uma etapa inicial de natureza quantitativa, constante de um Questionário 
Fechado, Autoaplicável, respondido pelos participantes. O objetivo da aplicação desse questionário foi 0 de conhecer melhor as Fraternidades em estudo, por meio de um levantamento sociodemográfico. Como não havia um questionário adequado para esse fim, 0 pesquisador, acompanhando a sugestão de Gil (1999), escolheu amelhor estratégiaa ser empregada, ou seja, a elaboração de um questionário específico para conhecer melhor as Fraternidades.

Conhecidas as Fraternidades pelo levantamento sociodemográfico, pôde-se definir um tema central para discussão no Grupo Focal. Nessa etapa utilizou-se um enfoque de natureza qualitativa com a finalidade de compreender melhor as Fraternidades em estudo. Teve-se a preocupação deconhecer ecompreender decomo os participantes da Fraternidade experienciam a espiritualidade, a partilha de vida e como entendem sua pertença ao grupo (Martins \& Bicudo, 1989).

Participaram da pesquisa 14 Fraternidades, perfazendo um total de 84 indivíduos pesquisados nas duas etapas do estudo. Após a realização dos procedimentos, já relacionados, foram elaborados D iários de Campo. De posse dos dados coletados realizaram-se diversas leituras compreensivas, emergindo uma questão central para ser discutida com quatro Fraternidades, numa segunda etapa, chamados Grupos Focais. A questão foi: Por que você integra esse grupo da Fraternidade Marista?

D e posse dos dados auferidos dos $\mathrm{G}$ rupos Focais e dos D iários de Campo, fez-se uma leitura preliminar, desprendidae flutuanteparaum primeiro contato com o todo da realidade das Fraternidades. A partir da compreensão resultante dessa leitura, realizou-se uma interpretação dos dados, por meio da discussão que segue.

\section{DISCUSSÃO DOS RESULTADOS}

A abordagem dos dados obtidos foi realizadamedianteaarticulação triangular: cruzaramse os dados empíricos com a psicologia dos pequenos grupos, articulada com a teoria sistêmica complexa e a reflexão do pesquisador que é coproduzida nos seminários do grupo de pesquisa, juntamente com 0 método. A palavra reflexão aqui é empregada no sentido dado por Morin (1990, 2005, p. 338-339), quando a define como "a aptidão mais rica do pensamento do pesquisador, o momento em que ele é capaz de se autoconsiderar, de se metassistemar," com a intenção de ir além das análises lineares habituais e da simples compreensão (Minayo, 2005). $\mathrm{Na}$ leitura reiterada dos dados auferidos, segundo a autora, dá-se particular atenção às contradições, às dissonâncias, numa relação dialogal também entre possíveis opostos, conformeo pensamento complexo de Morin (2005), destacando consensos e contradições em vista de novos aportes dessa vivência grupal, para a vida dos participantes do grupo, e para melhorias na rede social.

Dos Diários de Campo inferiu-se que a noção de rede está presente também nos pequenos grupos das Fraternidades porque estão organizadas com diferentes nós: cada uma possui um animador, um assessor e 0 relator das atividades. A rede também está presente na organização das Fraternidades por regiões, observando os limites territoriais das Províncias Maristas e, por fim, em rede internacional, formando o Movimento Champagnat da Família Marista, abrangendo 78 países onde os Irmãos Maristas estão presentes.

A realidade sociodemográfica das fraternidades levantada pelo questionário revelou que mais de cinquenta por cento têm acima de dez anos de existência. A mais antiga está com 16 anos e a vida média dos grupos pesquisados é de 10 anos. Existe também um índice elevado de fidelidade entre os participantes do grupo e raramentehá migração de participantes de um grupo a outro. Os grupos, por serem sistemas vivos, estão sujeitos à desorganização (entropia) e à reorganização (neguentropia), explica Morin (2005). Quando os participantes sentem instalar-se no grupo a tendência à desorganização, diz Enriquez (1991), exige de seus participantes condutas novas, confrontos com os imprevistos em si mesmos e com os outros para reverter essa tendência. $\mathrm{Na}$ pesquisa evidenciou-se que alguns gruposentraram em desorganização edesapareceram. Outros, porém, conseguiram reverter o processo graças aos meios que encontraram em si mesmos ena experiência primeira (Libânio, 1985) para reencetar o caminho. Outros permanecem na crise, como explica Enriquez (1991), porque ainda não tiveram a coragem de se aproximar do abismo e olhá-lo de frente. Enquanto permanecerem nesse marasmo, seu horizonte continuará nebuloso e o entusiasmo primeiro obscurecido e com pouco brilho.

A primeira pergunta formulada no questionário aplicado adez Fraternidadesfoi: Q uantos anos faz que a Fraternidade existe? As respostas das 
Fraternidades foram: Ir. Antônio Bortolini: 4; Família de Maria: 6; São Jacó: 7; Pio XII: 9; Mater D ei: 10; Medianeira e Terna Mãe: 11; São Pedro: 12; Ir. José Pasin: 13, e Assunção: 16 anos. Vemos aí uma oscilação entre 4 anos, a mais jovem, e 16 anos, a mais antiga. No entanto, das 10 questionadas, 7 têm 10 ou mais anos de existência, que vem a ser uma caminhada significativa quanto à duração.

Outro dado é o número de participantes das Fraternidades visitadas. A pesquisa revelou que das 14 Fraternidades estudadas, 10 possuem 8 ou mais integrantes. A Fraternidade mais numerosa, entre as pesquisadas, tem 13 participantes. Apenas 2 estão com 3 pessoas cada uma, portanto, abaixo da média, que é de 8.3 participantes por grupo. Perguntamos: Qual é o futuro de um grupo com apenas 3 indivíduos? Em princípio, não há limite mínimo nem máximo para que uma Fraternidade exista. No Projeto de Vida (Marista, 1990, p. 18) sugere-se que as Fraternidades tenham entre 4 e 15 participantes. Q uando o grupo cresce muito, sugerese que seja dividido, dando origem a uma nova fraternidade. Fica assim caracterizado que as Fraternidades dos Leigos Maristas são pequeno grupo (Seminotti, Borges \& Cruz, 2004).

Num diálogo entre a teoria dos pequenos grupos e a Teologia Bíblica, no que diz respeito à eficácia do pequeno grupo, pode-se fazer uma ancoragem com o livro de Isaías "Então o resto de Sião [...]" (Is 4,3) e com o livro de Sofonias: D eus deixará em Sião um povo pobre e humilde, o resto de Israel. Este resto lhe será fiel e Ele o abençoará (3,12-13). Logo, conforme a Bíblia, do pequeno resto, sairão as grandes mudanças. Isso é confirmado nas Parábolas do Fermento (Lc 13,21) e do Grão de Mostarda (Mt 13,31). Lemos na história das Fraternidades (Lefebvre, 1999) que os antigos alunos, ao deixarem a escola Marista, perderam 0 vínculo com o Espírito do Fundador e apossibilidade de reviver as experiências realizadas nas escolas. $\mathrm{Na}$ tentativa de reatar 0 vínculo, organizaram-se em redes de associações locais, depois regionais, nacionais e, por fim, criou-se a União Mundial. Sentindo-se impotentes em refazer a ruptura, recapturar o espírito perdido e simbolizálo em suas vidas, criaram-se, no ano de 1985, as Fraternidades Maristas, como tentativa de habitar o espaço e reapropriar-se do espírito do Fundador. Morin (2005), pormeio do princípio hologramático, explica essa recursividade que permite, nas pequenas unidades, reconhecer o espírito do todo.
Portanto, o espírito do Movimento como um todo, está presente na parte, que é a pequena Fraternidade.

As Fraternidades, primeiramente têm uma finalidade mais ad intra, isto é, a vivência da espiritualidade. Em segundo lugar, têm também uma razão de ser que aponta ad ex tra, qual seja, dar continuidade à missão deixada pelo Fundador do Instituto Marista: tornar Jesus Cristo conhecido e amado entre as crianças e os jovens. E como é isto para os fraternos? A pergunta do questionário sobre a questão da missão da Fraternidade, 77\% dos pesquisados responderam que está clara; 18\% que está meio esquecida; $5 \%$ que não está clara; e ninguém apontou a alternativa: não tem missão.

No Manual das Fraternidades (Marista, 1987, 1999, 2004) lê-se: "O primeiro trabalho apostólico do fraterno começa na própria pessoa e nafamília. O utro campo de apostolado éa profissão. D epois vem a comunidade, a Igreja" (2004, p. 14). Na concepção do manual percebe-se a interlocução entre aspectos básicos e restritos, quais sejam, a pessoa e a família. D epois cita áreas mais amplas, como a profissão, a comunidade, qual rede social, e a própria Igreja, como rede religiosa. Nessas, 0 fraterno defronta-se com emergências e interferências que exigem frequentes recursos à arte, fé e amor, a "trindade laica", nomeada por Morin (2006). Coexistem, assim, como acabamos de refletir, aspectos fundacionistas ou da tradição, e aspectos da complexidade, da diversidade do meio onde o fraterno realiza a missão. E este é 0 lado rico da missão, dentro de uma visão multidimensional e solidária, próprio da consciência da complexidade que traz no seu bojo a incerteza de que a ação apostólica da Fraternidade sempre será limitada, apesar de trazer em si a aspiração à plenitude, conforme o mesmo autor.

O utros dados que emergiram das respostas do questionário dizem respeito ao gênero e ao estado civil. No primeiro caso, 56\% dos participantes são homens e 44\% mulheres. 0 leitor certamente se pergunta: por que mais homens do que mulheres? A explicação, que parece ser pertinente, é que até meados da década de 1970, a maioria dos colégios maristas do Estado eram frequentados apenas por meninos, com exceção das Escolas Técnicas de Comércio e de Contabilidade, que eram noturnas. O sprofessores eram todos Irmãos Maristas. D epois, aos poucos, foi admitido algum professor leigo, e as professoras chegaram mais tarde, sendo hoje a 
maioria. Como muitos fraternos são antigos alunos, professores, pais de alunos, portanto, pessoas de meia idade ou mais, faz com que a maioria dos participantes seja homem. A outra questão é o estado civil. Constatamos que $50 \%$ dos que responderam ao questionário são casados, 34\% são casadas. Isso confirma os dados anteriores em que predomina o sexo masculino. Os quadros dos Colégios e Centros Sociais mantidos, hoje, pelos Maristas, no Estado, são diversos. A presença feminina é igual, se não maior do que a masculina. A tendência para 0 futuro é termos também mudanças na constituição das Fraternidades, quanto ao gênero eao estado civil, repercussões da crescente flexibilização da estrutura familiar na sociedade contemporânea (Baumann, 2003).

Sobre o nível sociodemográfico dos fraternos, a pesquisa revelou que há Fraternidades que vivem no centro das cidades, outras em bairros e outras ainda em pequenas cidades do interior do Estado. A origem e a classe social dos participantes formam um caleidoscópio variado e rico, fazendo com que as Fraternidades sejam grupos abertos e multifacetados quanto à dimensão sociodemográfica. Uma fala no Grupo Focal corrobora esta conclusão: "[...] a gente se torna irmãos e pessoas estranhas que moram distantes, e aqui a gente vira uma família."

Entre os fraternos entrevistados, o grupo predominante é dos que foram alunos Maristas, pais de alunos, antigos professores e auxiliares administrativos. Em segundo lugar vem um grupo misto de pessoas que foram funcionários de algum colégio ou obra social. No terceiro grupo predominam pessoas ligadas diretamente a alguma comunidade de Irmãos, estabelecida em região carente, em meio a um bairro ou cidade do interior. Nas três situações descritas, existe sempre um vínculo com uma comunidade de Irmãos, preservando assim o caráter espontâneo, gratuito e filantrópico da pertença à Fraternidade. Predomina assim a liberdade de permanecer ou não, assim como um espaço de amizade, bem-querer, ajuda mútua, amor fraterno, como se fossem irmãos de sangue. "O meu motivo hoje de estar no grupo é a espiritualidade, mas compartilhada com os demais para além da minha família de sangue" $\left(\mathrm{GF}^{1}\right)$.
Os caminhos percorridos pelas pessoas até chegar à Fraternidade são bem variados. O resultado do questionário não apresentaumaprevalênciamaior, a saber: $43 \%$ chegaram por meio de um familiar; $24 \%$ por causa do trabalho com os Irmãos; $23 \%$ por intermédio de um amigo, que, em muitos casos, foi um Irmão Marista, e os 10\% restantes têm motivos vários. Podemos nos perguntar ainda: qual o grau de parentesco dos fraternos com algum Irmão Marista? Nas respostas colhidas constata-se que $47 \%$ dos participantes das Fraternidades têm algum familiar ligado aos Maristas, enquanto a maioria (53\%) não tem. Esses dados nos induzem a pensar que diversos caminhos são percorridos para se chegar a um grupo da Fraternidade Marista. $\mathrm{O}$ fator familiar vem citado em segundo lugar, com relativa força. As pessoas que entraram no grupo e não têm uma ligação mais estreitacom osIrmãos Maristas, estariam procurando, no Movimento, um espaço de participação social? Em certos casos, isso até pode ser verdade, mas em outros, os motivos vêm um tanto mesclados e é difícil de afirmar uma ou outra coisa. No Grupo Focal alguém declarou: "E procurar distribuir amor, atenção aos outros, é procurar ser humano dividindo o pouco que temos, nem que seja com um sorriso."

No questionário, foi perguntado: Qual é o motivo que você tem para estar na Fraternidade Marista?66\% das respostas apontaram como motivo principal de pertença ${ }^{2}$ à Fraternidade 0 aprofundamento da Espiritualidade Marista. Uma falado G rupo Focal diz: "Basicamenteépormotivos espirituais, religiosos que existe este grupo." Em segundo lugar vem a vivência cristã, com 15\% de indicações. Umapessoa declarou: "Todosnóstemos a prática de estar junto nos sacramentos de nossa Igreja, de cultivar isto, ir à missa." Estabelecendo uma interface entre o olhar psicológico e 0 saber teológico, encontramos que vivência cristã e vivência da Espiritualidade Marista são aspectos complementares da fé cristã, recebida no batismo. A espiritualidade Marista é uma forma peculiar de viver a espiritualidade cristã, isto é, com as características do espírito do seu Fundador. Esta questão é confirmada por uma fala, no Grupo Focal: "Então, num ambiente onde Jesus Cristo está é um ambiente de partilha, de amizade, e é um ambiente de vivência Marista, também." Somando-

\footnotetext{
1 Grupo Focal.

2 Como pertença, entendemos os laços existentes entre os fraternos dos grupos. A poiando-se na Psicanálise, tomamos apalavra laço como sinônimo de vínculo. Pichon-Rivière (2000, p. 3) amplia o seu significado, concebendo-o como "a maneira particular de o indivíduo se relacionar com o outro ou outros, criando uma estrutura particular a cada caso e a cada momento."
} 
se os $66 \%$ atribuídos à Espiritualidade Marista, com os $15 \%$ que indicaram a vivência cristã, alcançamos um total de $81 \%$ dos pesquisados que apontou a vivência da Espiritualidade cristã e Marista como o principal motivo da pertença à Fraternidade. Mas, onde isso é mais confirmado? $\mathrm{Na}$ discussão do Grupo Focal, alguém falou: "Cultivamos a família, a espiritualidade na família. E um valor forte estar juntos nos sacramentos de nossa Igreja, que é a católica." O utra pessoa assim se expressou: "Hoje a gente acha que vive bem a nossa espiritualidade, tem o apoio do grupo, embora continue frequentando a Igreja." Nos diários de campo foi observado que três das Fraternidades pesquisadas reuniram-se após terem participado juntas da celebração da missa, sendo que uma Fraternidade animou a missa como equipe de liturgia. "Os trabalhos que a gente faz também, como amissa, quea gentetem nanossa comunidade" (G F). Algum participante, relacionando a dimensão espiritual com o compromisso com o outro, assim se expressou: "Essa busca, por exemplo, dessa socialização espiritual, é porque nós estamos de certa forma, nos complementando no outro."

Junto com o motivo espiritual e de forma muito colada, vai a questão humana da amizade, da valorização das pessoas e do acolher. Reportandonos à história da origem das Fraternidades e ao "vale" 3 em queforam engendradas, podemosentender que certas atitudes dos Irmãos deixaram marcas indeléveis nas personalidades dos jovens educados por eles. D essa forma assimilaram as virtudes do espírito marista, entre elas, as chamadas violetas maristas: humildade, simplicidade e modéstia. "Um exemplo de vida dos Irmãos, uma maneira diferente de evangelizar, de valorizar e de acolher" (GF). Junto às violetas maristas está 0 espírito de família, amor ao trabalho, a devoção a Maria, em particular no seu modo discreto de servir, presente no recado dado aos servos, nas Bodas de Caná: "fazei tudo o que Ele vos disser" (Jo 2,5). Esse "jeito marista" deixou marcas na vida e na personalidade dos que eram orientados por eles, a tal ponto que nunca se esqueceram dessa forma diferenciada de serem tratados. Pelo contrário, fazem de tudo para continuar a viver e a passar esses valores às futuras gerações. "Eles (os filhos) estão se criando, se educando, formamos uma família que cultiva Cristo" (GF).
A amizade, mais relacionada com 0 jeito de ser e acolher dos Irmãos Maristas, tratada anteriormente, aqui vem enriquecida com a ideia mais relacionada ao amor, à tolerância, ao suporte, à atenção, ao prazer de estarjunto, na Fraternidade. O s fraternos a vivenciam assim: "Ao sairmos de cada reunião, já sentimos falta de outra reunião, porque criou-se aí um grande amor, um amor fraterno e com isso nós avançamos" (GF). Para Aliatti (2004 apud Giner 1995):

O processo deurbanização edeindustrialização, eisolamento social urbano, passouaseconstituir como o modo de existência contemporâneo. Este modo é marcado por uma carência de vínculos sociais significativos, estabelecendo-se a idéia das relações impessoais, superficiais, transitórias e segmentadas do espaço urbano.

Para suprir essa carência apontada pela autora, o espaço familiar da Fraternidade sugere ser um lugar apropriado para se cultivar esses laços de amizade, amor, suporte, tolerância, desabafo, estímulo mútuo e até para partilhar vivências, dificuldades no emprego, na relação entre o casal, com os filhos e com outras situações de fora do grupo. "Então é o lugar onde cada um é bem transparente, secolocacomo é, com suaslimitações, seus valores, suas contribuições" (GF).

O s encontros festivos, tanto de recordação como de celebração, que eram os motivos principais para reencontros dos antigos alunos, referidos anteriormente, continuam presentes nas respostas dadas ao questionário, porém de forma um pouco mais atenuada, com $8 \%$ das respostas. A fala de uma pessoa, no grupo focal, diz: " $E$ a reunião da gente é normalmente uma festa, por isso costumam chegar 19h30min, outros 20h30min. Não tem hora para começar, nem para terminar. Não é uma coisa muito convencional. É um encontro devida mesmo. Estamos contextualizados." D esse dado dos 8\% da festa, somado ao item convívio (24\%), resulta um total de $32 \%$. Acrescentando o fator conforto e suporte, que representa 3\% das respostas, atingimos um total de $35 \%$. Significa que essa parte humana da companhia, suporte mútuo, conforto e festa presentes na motivação dos primeiros ex-alunos para retornar à escola em que estudaram, continua

\footnotetext{
$\overline{3}$ Trata-se do vale do Rio G ier, em l'H ermitage, França, onde Champagnat construiu o berço do Instituto Marista.
} 
presente nas Fraternidades de hoje. E a fala de um fraterno parece confirmar esta realidade:

O grupo é algo muito importante para minha vida. Por quê? Em primeiro lugar somos todos muito amigos, temos uma amizade muito grande entrenós, um precisa de suporte, outro atende. Então, a amizade é muito importante e forte em nosso grupo.

\section{Outra afirmou:}

É pensar no outro muito positivamente, até com concessões para ranços e rabugices que nós temos, mas até de ser assim tolerantes a isso, não valorizando ou supervalorizando outros aspectos de parceria e amizade, enfim, de descontração e de momentos de falar mais ou falar menos.

Além da espiritualidade e da amizade como motivos que mais atraem os fraternos aos grupos, "háo carismadeChampagnat, dos Maristas, que é uma maneira diferente de viver o grupo" (GF). Outra pessoa assim se expressou: "Uma maneira feliz, uma maneira alegre, e aí, eu me senti bastante cativado". Aqui se percebe que muitos fraternos não estabelecem uma distinção entre a dimensão humana, referida no parágrafo anterior, com suas particularidades, e os aspectos do carisma de Champagnat (Maristas, 1997, C 2,3,4), a saber: a espiritualidade (Maristas, 1997, C 7); as três violetas (Maristas, 1997, C 5); 0 amor a Maria e a união com Deus (Maristas, 1997, C 17), entre outras. Transparece assim uma inter-relação entre essas duas dimensões. As demais alternativas da pergunta eram: Estudo do Fundador, com 18\% e trabalho com os Irmãos, 5\%. Esse resultado indica que a tendência de querer continuar a viver a espiritualidade e as práticas maristas da escola ou de alguma outra situação de contato com os Irmãos persistem, de forma semelhante, nos fraternos de hoje, como aconteciacom os primeiros ex-alunos dos Irmãos, lá nos primórdios da fundação do Instituto Marista. Ainda sobre 0 carisma marista, uma fala declarou: temos um "encantamento pela vida de São Marcelino Champagnat". "São Marcelino, nós 0 invocamos todos os dias em nossas orações", falou outra pessoa. E um terceiro participante disse: "Nós somos apaixonados pelos Maristas". E ainda: "E sse momento de estar com outros casais para o cultivo da espiritualidade, do carisma Marista, como é bom, como é reconfortante" (GF). Essa forte atração pelo carisma e vida de São Marcelino, entendido a partir de um ponto de vista religioso, como força do Espírito Santo, pode se entendida também, a partir do ponto de vista da Psicologia, como força motivadora que põe em movimento as energias intelectuais, afetivas e comportamentais do indivíduo. Esses três componentes das atitudes, de forma integrada e recursiva, constituem as condições ideais para a internalização dos valores do Carisma de São Marcelino, tanto na vida privada como na social, assim como seu testemunho por meio da missão e dos gestos de caridade que realizam em seu entorno. Isso se torna mais compreensível quando referido ao espírito do Fundador, constituído pelas virtudes de humildade, simplicidade e modéstia, pelo o amor ao trabalho, 0 amor à família e à pessoa de Maria, como mãe e educadora do menino Jesus, modelo do seu ideário pedagógico. São Marcelino fundou o Instituto Marista em 1817, e com seus quase duzentos anos de existência, continua a ser inspiração e ponto de referência para a vivência da espiritualidade pelos Leigos Maristas das Fraternidades, em nossos dias.

Outro tema que emergiu é a questão familiar eas modalidades deconstituição dos grupos. A palavra família aparece no nome do Movimento. E qual é o motivo da inclusão do termo no nome? Na maioria das Fraternidades, é o casal que participa do grupo. No entanto, em algumas, os filhos adolescentes, e, em outras ainda, as crianças participam, porém não em tempo pleno. No Diário de Campo lê-se: "Numa Fraternidade, depois da abertura do encontro, as crianças foram para uma sala contígua, onde receberam uma tarefa relacionada com 0 assunto do encontro". E ainda: "Terminadaa discussão, as crianças foram chamadas e, no meio do círculo, apresentaram o que tinham realizado ealgumas pessoas fizeram perguntas sobre o significado da tarefa e elas explicavam, com muita alegria, o que tinham realizado."

D entro da compreensão expandida do termo família, encontramos uma Fraternidade formada só de homens, antigos alunos, exfuncionários administrativos ou ex-professores de alguma escola marista. E imediatamente surge a pergunta: E como fica a questão família nessa modalidade de viver Fraternidade Marista? Baseando-nos em Morin (2006, p. 122), isso é possível pelo princípio de inclusão, "posso 
inscrever um "nós" em meu "Eu", como eu posso incluir meu "Eu" em um "nós", assim, posso introduzir, em minha subjetividade e minhas finalidades, os meus parentes, meus filhos, minha família, minha pátria." D essa forma, mesmo que esteja só o marido, a família está incluída, e assim não se colide com o que foi idealizado e escrito no nomedo movimento: Movimento Champagnat da Família Marista. Temos aqui mais um motivo por que se reúnem nas casas das famílias. Confirma-se assim o princípio hologramático do pensamento complexo de Morin (2006, p. 74), pelo qual "não apenas a parte está no todo, mas o todo está na parte".

A respeito da pergunta sobre o motivo de estarem na Fraternidade, as resposta foram: 66\% para aprofundar a Espiritualidade Marista; $15 \%$ para buscar a vivência cristã; $8 \%$ para acompanhar o cônjuge; $6 \%$ para reviver o que tinha aprendido; 3\% para realizar ações sociais e $2 \%$ não especificaram o motivo. No início da elaboração do Projeto, o pesquisador tinha a intuição de que um considerável número de fraternos aderia à Fraternidade Marista para reviver experiências passadas. Porém, nas respostas obtidas pelo questionário apenas $6 \%$ assinalaram essa alternativa. "Foram momentos muito felizes da minha vida enquanto jovem" (GF). Talvez nos perguntemos: Por que só seis por cento apontaram essa alternativa? Esse percentual baixo não derruba a intuição do pesquisador? Pode-se ainda entender que, mesmo que a maioria (66\%) apontasse o aprofundamento da E spiritualidade Marista como motivo de estar na Fraternidade, essa questão da revivescência também está contida nessa resposta majoritária, uma vez que aquele que se liga ao grupo, para aprofundar a espiritualidade Marista, com certeza 0 faz também porque, em algum momento, vivenciou-a como algo positivo e significativo em sua vida e que agora deseja reviver. Uma fala do G rupo Focal assim se expressou:

Então, aliás, essa amizade, esse amor que a gente sente dentro do grupo também tem 0 carisma de Champagnat, dos Maristas, que foi uma maneira diferente de viver o grupo. Uma outraperspectiva, umaoutramaneira deencarar o crescimento espiritual muito grande, um apoio, tá faltando a palavra, é o exemplo de vida dos Irmãos, uma maneira diferente de evangelizar, de valorizar e de acolher.
À pergunta sobre o que aconteceu de mais significativo na Fraternidade, os participantes responderam: a oração e a espiritualidade $49 \%$; 0 convívio 24\%; 0 estudo do Fundador 18\%; 0 trabalho com os Irmãos 5\%; a solidariedade $2 \%$; e outras $2 \%$. As preferências pela oração e espiritualidade, somadas ao percentual do convívio e do estudo do Fundador perfazem um total de 91\% das respostas dadas pelos pesquisados. Esse percentual alto assinala que as experiências mais significativas da pertença à Fraternidade estão relacionadas à espiritualidade e às relações humanas. Os 5\% que apontaram ser o trabalho com os Irmãos o motivo da pertençaà Fraternidade dá a entender que o vínculo duro (Deleuze \& G uattari, 1995), isto é, ser funcionário do Instituto Marista, tem pouca força para manter uma pessoa por muito tempo no grupo. Advindo uma crise nas relações de trabalho, esse vínculo geralmente se rompe e, se não existe outro mais forte, a pessoa pode se retirar da Fraternidade. D essa forma, evidencia-se que 0 vínculo mais duradouro para manter alguém no grupo está além das relações de compromisso. A fala no G rupo Focal exemplifica esta relação: "Volta muita vezes o convívio entre amigos, as amizades, a partilha de vida, a festa como algo muito marcantee destacado nas relações dos participantes da Fraternidade."

O utro dado evidenciado pela compreensão dos resultados do questionário é o grau de satisfação dos participantes da Fraternidade. 62\% muito satisfeitos com o grupo; 27\% satisfeitos: "Nós somos felizes no jeito marista de ser" (GF), e 11\% pouco satisfeitos. Ligando-se a questão do grau de satisfação por estar no grupo com aquela do desejo de abandonar o grupo, constata-se, nesta última pergunta que 48\% nunca pensaram em abandonar o grupo. Acrescido dos $10 \%$ que jamais o fariam, obtemos um total de $58 \%$ de fidelidade ao grupo. Somando os $31 \%$ que pensaram em abandonar uma vez, mas não 0 fizeram, obtemos um percentual de $89 \%$ de participantes que são fiéis ao grupo. E até os 11\% que pensaram em abandoná-lo diversas vezes, porém não o fizeram, levam-nos a concluir que, em geral, os grupos são estáveis e que sua grande maioria não os abandona tão facilmente. O corre aqui uma coincidência. $O$ percentual que aparece em terceiro lugar na pergunta anterior, com a formulação de 'pouco satisfeito', isto é, 11\%, se repetenaperguntaa seguir, porém com aformulação 
de 'diversas vezes'. Isso faz pensar que nas Fraternidades nem sempre as coisas estão 100\% e que existem discordâncias, choques de opiniões, descontentamentos em relação a colegas ou ao animador. Porém, em se tratando de questões normais no funcionamento de grupos, elas são toleradas, contornadas e não chegam a ser causas suficientes para retirar-se da Fraternidade. A pesar dessas limitações, constata-se uma constância, comprovada pelos índices alcançados pelas somas das duas primeiras questões em ambos os resultados em discussão. Assim, estar na Fraternidade parece ser um ato de escolha pessoal e livre, possibilitandose ao indivíduo, o tempo todo, retirar-se ou permanecer no grupo. Há liberdade para estar ou não no Movimento. Sobre a possibilidade de abandonar o grupo, alguém assim se expressou:

\begin{abstract}
Então, hoje, por mais atividades que cada jovem tenha, abandonar o grupo não está em hipótese nenhuma em nossas cabeças. Porque o grupo já é referência de vida para nós. É uma experiência viva, de partilha, experiência viva de crescimento do grupo, de ajuda mútua, experiência viva de ser e estar como cristãos. A genteconsegue partilha, simplicidade, um ajuda o outro, ajuda mútua, nós somos uma grande família (GF).
\end{abstract}

A fidelidadeao grupo vem coladaà questão da satisfação por pertencer a ele, ilustrada na pergunta que segue: “O que lhe dá mais satisfação?”. Os pesquisados responderam: $39 \%$ os momentos de celebração; 34\% o convívio; $11 \%$ as confraternizações e momentos de alegria; $8 \%$ a partilha de dificuldades; 3\% a ajuda mútua; 3\% 0 conforto esuporte; e2\% 0 animadordaFraternidade. Somando os percentuais das alternativas colocadas entre as extremas que falam do convívio, confraternizações, alegria, partilha de dificuldades e ajuda mútua, alcançamos um percentual significativo de 59\%. Ficou acima do percentual alcançado pela alternativa dos momentos de celebração, assinalando que a dimensão humana entre os membros das Fraternidades émuito intensa, significativa e muito apreciada pela maioria.

0 aporte à educação dos filhos, evidenciado pela pesquisa, não estava contido nos objetivos específicos relacionados aos possíveis ganhos da pertença à Fraternidade. Vejamos o que foi dito no G rupo Focal: "[...] Jamais quero parar, porque é um exemplo que a gente dá para os filhos, é um ensinamento, uma catequese. Eles estão se criando, se educando, uma família que cultiva Cristo." E outra pessoa assim falou: "É uma escola para os nossos filhos, é o caminho de educação dos nossos filhos, e depois numa visão mais geral, é um meio de a gente melhorar a sociedade." Então, ganha a família porque o grupo é uma escola para os filhos e não pára aí, melhora também 0 ambiente social.

As afirmações anteriormente citadas a respeito de alguns valores, do ambiente da Fraternidade, que incidem sobre a vida dos filhos e do meio social, com certeza devem ter chamado atenção. O utras falas no $\mathrm{G}$ rupo Focal ampliam essa contribuição, referindo-a também à vida pessoal dosfraternos. "A Fraternidade tem essacontribuição para a vida de cada um de nós." "Eu acho que a gente encontra suporte e reforço na Fraternidade." Essa ideia foi intuída pelo pesquisador quando, num dos objetivos, aludia a uma possível contribuição para a vida pessoal do fraterno e para o seu meio. Pela ênfase das falas dos participantes, percebe-se queéumaforçanaajudaentreo indivíduo e seu meio ${ }^{4}$, em recursão organizacional (Morin, 2005), como crescimento, processo formativo pessoal dos participantes e de melhoria do seu meio social. Isso é confirmado por algumas falas dos Grupos Focais: "Em primeiro lugar aqui eu cresci espiritualmente, desde o início. Modifiquei meu modo de vida". "Também cresci como pessoa". "Hoje participamos também de um grupo de caridade, e distribuímos alimentos, roupas." Enquanto se dialogava sobre as influências no todo da família, um fraterno disse: "E sta semana eu tive uma surpresa de uma das filhas: ela fez um gesto que não esperava dela." Temos aí a recursividade, ou seja, o que os pais vivem e passam para os filhos, retorna aos primeiros em forma de satisfação e bemestar ao presenciar tais atitudes nos últimos.

A pergunta sobre a atividade principal da fraternidade, $71 \%$ apontaram a oração e a partilha. Logo em seguida vêm várias ações sem predominância de uma específica, com $27 \%$. No Grupo Focal especificaram uma destas ações e a chamaram de ação concreta. Isso demonstra que a

\footnotetext{
${ }^{4}$ D eleuze e Guattari (1995) denominam essa ação em dois sentidos de agenciamento, em que uma coisa puxa a outra e esta é puxada pela primeira.
} 
dimensão social dá um equilíbrio ao grupo, constituindo-se quase como o fiel da balança para escapar da polaridade do só oração e partilha de vida ou só ação social. Na fala que segue, evidenciase o que já se acenou nos objetivos específicos: há um aporte social. Portanto, ganham as comunidades em que estão inseridos, onde praticam ações ligadas à religião, promovem 0 bem-estar social e a cidadania. "As notas fiscais recolhidas foram doadas e a instituição (que as recebeu) já comprou ventiladores, cortinas, material pedagógico e de expediente" (GF).

A Fraternidade tem um objetivo não declarado, que subjaz ao s explicitados pela pesquisa. E o espaço da Fraternidade, que, parafraseando Morin, pode ser chamado de espaço lúdico, poético e da gratuidade. Isso pode ser decorrente da tendência de escapar do prosaico, da utilidade e da necessidade de produzir e apresentar resultados. 0 grupo da Fraternidade oferece-se como esse ambiente para, como disse uma fala: "Procurar distribuir amor, atenção aos outros, é procurar ser humanos dividindo o pouco que se tem". Segundo Morin (2005, p. 45), "a poesia nos leva à dimensão da existência humana. Revela que habitamos a Terra, não só prosaicamente - sujeitos à utilidade e à funcionalidade - mas também poeticamente, destinados aos deslumbramentos, ao amor, ao êxtase." A poesia, diz ainda Morin, por meio da linguagem, coloca-nos em comunicação com 0 mistério, que está além do dizível. Um fraterno tentou dizer isso quando falou: "Talvez a materialização dessa comunicação superior não venha através de coisas materiais, mas ela vem exatamente por esse sentimento que, às vezes, nós nem conseguimos expressar" (GF).

\section{CON SIDERAÇÕES FINAIS}

Ao final da pesquisa, evidencia-se que a espiritualidade, com seus diferentes enfoques, é o motivo principal da pertença à Fraternidade Marista. Além disso, a partilha de vivências é outro motivo, juntamente com o aporte que traz 0 convívio na Fraternidade para o crescimento, 0 bem-estar do participante, da família, com repercussões positivas na comunidade onde se insere. E videnciou-se também que alguns fraternos entram no grupo para reviver experiências passadas, mormente aquelas relacionadas $\mathrm{com}$ a espiritualidade, a oração e momentos festivos. $\mathrm{Na}$ atualidade, essas são enriquecidas por um enfoque novo, ou seja, o desejo de aprofundar a espiritualidade e a vida do Fundador.

Sobre os ganhos pela pertença à Fraternidade, emergiu mais um: a ajuda na educação dosfilhos. Referiam-setanto aosfilhos queparticipam dos encontros como aos demais, que também são beneficiados, porque toda a família cresce quando um ou mais membros crescem nas Fraternidades.

Revelou-se como uma grande força 0 amor e a paixão dos fraternos pelo Fundador, sua vida e pela vida dos Irmãos Maristas. É notável como o dinamismo que haurem dessas fontes torna-se inspiração e impulso para a vida pessoal, a dedicação à família, ao trabalho profissional, às obras sociais e à evangelização que realizam.

A fidelidade ao grupo e à amizade profunda que nele cultivam são outras evidências da pesquisa. A partir dessa vivência e partilha, vão crescendo e ajudando outros a crescer. No entanto, as considerações até aqui relacionadas não esgotam a compreensão e o entendimento do tema em estudo, permanecendo outros elementos que podem ser aprofundadosacercadas FratemidadesLeigas Maristas, como espaço de grande sinergia humana e espiritual.

\section{REFERÊNCIAS}

Aliatti, I. Processos dos grupos psicológicos construtores da pertença: Vínculo da amizade, organizadores grupais e o lugar espaço potencial. D issertação de Mestrado, Pontifícia Universidade Católica do Rio G rande do Sul, Porto Alegre.

Alves, M. C., \& Seminotti, N. A. (2006). O pequeno grupo e o paradigma da complexidade em Edgar Morin. Psicologia USP, 17(2), p. 113-133.

Anzieu, D. (1978). El grupo y el inconsciente. Madrid: Biblioteca Nueva.

Back, K. W. O pequeno grupo: corda bamba entre sociologia e personalidade. (Trad M. N. de Oliveira). Recuperado 20 maio 2009, disponível em http:/ / www.continents.com/ art2.htm

Baumann, Z . (2003). Comunidade: A busca por segurança no mundo atual. Rio de Janeiro: Zahar. 
Bíblia de Jerusalém. (2002). Evangelho de São João. São Paulo: Paulus.

Delleuze, G., \& Guattari, F. (1995). Mil platôs: Capitalismo e esquizofrenia. Rio de Janeiro: Ed. 34.

Enriquez, E. (1991). 0 trabalho da morte nas instituições. In R. Kaës, J. Bleger, E. Enriquez, F. Fornari, P. Fustier, \& R. Roussilon et al. Instituição e as instituições (pp. 73-101). São Paulo: Casa do Psicólogo.

Gil, A. C. (1999). Métodos e técnicas de pesquisa social. (4a ed). São Paulo: Atlas.

Giner, J. C. (1995). La amistad-perspectiva antropológica. Barcelona: Icaria.

Kivitz, E. R. (2007). Espinitualidade no mundo corporativo: Aproximações entre prática religiosa e vida profissional. Dissertação de Mestrado, Faculdade de Filosofia e Ciências da Religião, Programa de Pós-G raduação em Ciências da Religião, Universidade Metodista de São Paulo. São Bernardo do Campo.

Lefebvre, A. (1999). D os antigos alunos ao movimento Champagnat da família Marista. Cadernos Maristas, 1(15), 119-170.

Libânio, J. B. (1985). Discernimento vocacional: A experiência fundante. Convergência. 20(182), 195-220.

Maturana. H. R., \& Varela, F. J. (2005). A árvore do conhecimento: As bases biológicas da compreensão humana. (5a ed.). São Paulo: Palas Athena.

Minayo, M. C. de S. (2005). Avaliação por triangulação de métodos: Abordagem de programas sociais. (20. ed.). Rio de Janeiro : FIO CRUZ.

Marista, Movimento Champagnat da Família [1990?]. Projeto de vida. Porto Alegre: Centro Marista de Comunicação.

Marista, Movimento Champagnat da Família. (1987, 1999, 2004). Manual das Fraternidades. GT-Leigos, 1(3), 1-36.

Maristas, Instituto dos. (1997). Constituições. São Paulo: Loyola.
Maristas, Instituto dos. (2007). Água da Rocha. São Paulo: FTD.

Morin, E. (1990). A cabeça bem-feita: Repensar a reforma, reformar o pensamento. (12a ed). Rio de Janeiro: Bertrand Brasil.

Morin, E. (2005/ 2006). Introdução ao pensamento complexo. Porto Alegre: Sulina.

Martins, J. E., \& Bicudo, M. A. V. (1989). A pesquisa qualitativa em psicologia: Fundamentos e recursos básicos. São Paulo: Moraes.

Musso, P. (2001). Gênese et critique de la notion de Réseau in parrochia, D. Seyssel. France: Champ Vallon.

Seminotti, N., Borges, B., \& Cruz. J. (2004). O pequeno grupo como organizador do ambiente de aprendizagem. Revista USF, 9(2), 181-189.

Serres, M. (1994). La legende des anges. Paris: Flammarion.

Recebido: 25/ 08/ 2008

Received: 08/ 25/2008

Aprovado: 19/11/ 2008

A pproved: 11/ 19/ 2008

Revisado: 04/ 08/ 2009

Reviewed: 08/ 04/ 2009 